Gut, 1977, 18, 717-720

\title{
Carbenoxolone sodium capsules in the treatment of duodenal ulcer
}

\author{
An endoscopic controlled trial ${ }^{1}$
}

SUMMARY Eighty-six patients with duodenal ulcer were treated in a multicentre controlled trial with carbenoxolone capsules (Duogastrone, $50 \mathrm{mg}$ four times a day for six weeks) or a placebo. Sixtynine patients accepted endoscopy at the beginning and end of the treatment. Symptomatic responses and endoscopic improvement were significantly greater in those receiving the active preparation than in those receiving the control capsules, complete, endoscopically assessed, healing being achieved in $65 \%$ and $20 \%$, respectively, of individuals having accepted endoscopy, after six weeks' treatment. Side-effects of salt and water retention or hypokalaemia were noted in over a quarter of those receiving the carbenoxolone capsules, but none of the adverse effects was severe enough to necessitate withdrawal of treatment.

\begin{abstract}
Although there is a clear evidence that treatment with carbenoxolone sodium will accelerate the healing of gastric ulcer, the value of the drug in duodenal ulcer has been contested. When it is given in tablet form it appears to be inactive, possibly because absorption occurs in the stomach. A capsule was therefore devised that would release its contents directly into the duodenum. Some have concluded that even in this form there is no evidence of any useful clinical effect (Colin Jones et al., 1968; Cliff and Milton Thompson, 1970), whereas others have found that the drug does induce symptomatic improvement and/or ulcer healing (Craig et al., 1967; Archambault et al., 1975). Much of this confusion may have arisen because investigators have relied upon small series of patients in reaching their conclusions, or else because direct endoscopic evidence of healing was obtained. We therefore treated a substantial number of patients with active duodenal ulceration (as judged by symptoms and endoscopic evidence of disease) with carbenoxolone sodium capsules or with an apparently identical placebo.
\end{abstract}

${ }^{1}$ Those taking part in the trial and the centres at which it was carried out are as follows:

J. Sahel, H. Sarles (Marseille: U31 INSERM), J. Boisson (Paris), J. Bonnet-Eymard (Grenoble), A. Cornet (Paris), J. Delmont (Nice), J. Dubarry (Bordeaux), R. Dupuy (Paris), R. Gisselbrecht (Besançon), H. Monges (Marseille), A. Ribet (Toulouse), A. Roberti (Lagny), A. Valla (Caen), J. P. Weill (Strasbourg). Mathematical study: R. C. Cros (U31 INSERM)

Received for publication 24 February 1977

\section{Method}

Treatment was given for six weeks in the form of capsules containing $50 \mathrm{mg}$ carbenoxolone sodium in a delayed release form (Duogastrone) or with an identical placebo capsule in which lactose replaced the carbenoxolone. Each patient received three boxes, each one containing 60 capsules of either the placebo or the active product. A similar number of boxes containing placebo or active product was prepared. Each set of boxes was randomly allotted a number and the key remained secret until the end of the trial, so that neither the physician nor the patient knew which treatment the patient was receiving. Each individual was instructed to swallow one capsule 30 to 60 minutes before each of the three main meals of the day, morning, midday and evening, taking an extra capsule at $4 \mathrm{pm}$ in the afternoon.

Patients were excluded from the trial if they were 70 years old or more, if they had an associated gastric ulcer, if symptoms were sufficiently severe to warrant surgery, or if they had complicating cardiovascular, pulmonary, or renal disease. Those included in the trial all had a characteristic ulcer history and active symptoms as judged during a week's observation when antacid treatment alone was given between the initial radiological diagnosis and confirmation of active ulceration by endoscopy. Information regarding clinical, biological, radiographic, and endoscopic symptoms was collected in a standardised questionnaire. Patients were advised to reduce their smoking and intake of alcohol, but to continue with a normal diet, excluding only items which they considered 
caused pain; they were also recommended to continue with their normal daily routine wherever possible. Antacid drugs were given for the relief of pain, but no other drugs, and all patients were advised not to take salicylate analgesics or other anti-inflammatory drugs.

Treatment was conducted at 13 different hospital centres in Besançon, Bordeaux, Caen, Grenoble, Lagny, Marseille, Nice, Paris, Strasbourg, and Toulouse and each centre was supplied with separate randomised sets of the test and placebo preparation in groups of six containing three test and three placebo.

Those treated were seen every two weeks when their weight and blood pressure were determined and the presence or absence of ankle oedema was noted, as were any spontaneous complaints of side-effects. Patients were also asked about the frequency and severity of pain, the amount of antacid which they had taken, and about their smoking habits and alcohol consumption.

At the first and last visits blood samples were taken for full blood count, urea and electrolyte determination, and measurements of serum transaminases, alkaline phosphatase, lactic dehydrogenase, and bilirubin. Endoscopy was performed before treatment and repeated by the same endoscopist at the end of six weeks.

Endoscopic results were graded as follows: $3=$ ulcer still present, unchanged in size or larger; $2=$ ulcer still present but smaller; $1=$ ulcer almost invisible or inflammatory changes only detectable; $0=$ ulcer healed and no persistent inflammatory changes.

\section{Results}

One hundred and two patients were initially included in the trial, 53 receiving capsules containing carbenoxolone and 49 the placebo. The two groups contained almost equivalent numbers of men and women, 47 men and six women receiving carbenoxolone capsules and 44 men and five women the placebo. The groups were also of equivalent age

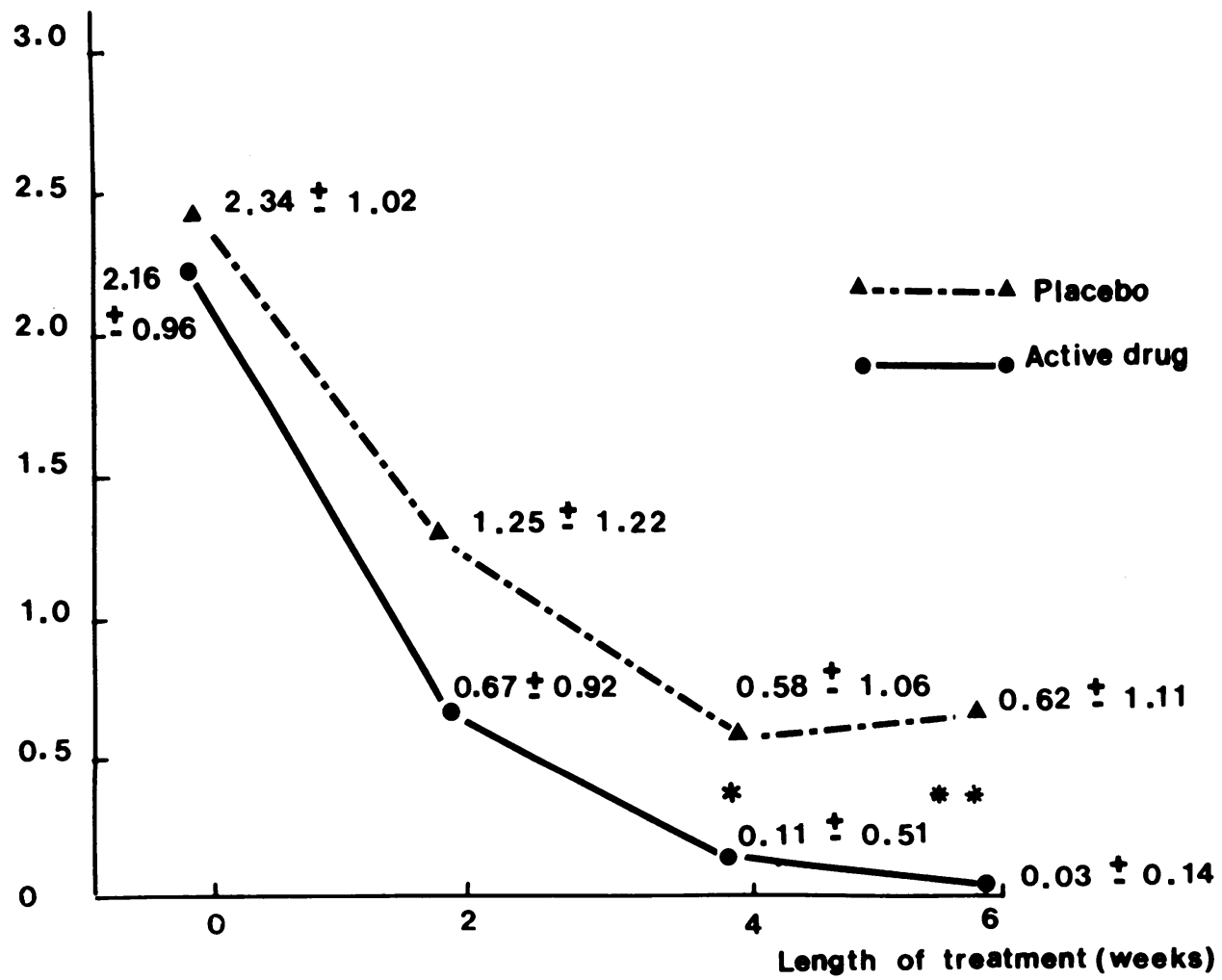

Figure Average number of attacks per day and per patient $\left({ }^{*} \mathrm{P}<0.021^{*} \mathrm{P}<0.01\right)$ 
distribution $45 \pm 14.4$ and $46 \pm 14.8$ (mean \pm SD) years respectively. Sixteen patients (seven $(13.21 \%)$ treated by carbenoxolone capsules, nine $(18.37 \%)$ treated by placebo) failed to complete the full course of treatment, either because they did not reattend for assessment or because they were withdrawn because of continuing severe symptoms.

Sixty-eight of the 86 patients who completed the trial were submitted to endoscopy at its beginning and end, and the results are shown in Table 1;18 patients refused the second endoscopic examination. Twenty-four out of $37(64.9 \%)$ of those receiving the carbenoxolone capsules had ulcers which completely healed during treatment and in another seven $(18.9 \%)$ healing was almost complete. In contrast, only six patients of the $31(19.4 \%)$ receiving placebo had ulcers which completely healed, and another nine $(29.0 \%)$ had almost complete healing. This overall difference in healing is highly significant statistically $\left(\chi^{2}=19.0, \mathrm{n}=3, \mathrm{P}<0.001\right)$. Calculated on the healed/unhealed basis, the difference is also significant $\left(\chi^{2}=4.76, \mathrm{P}<0.05\right)$.

Table 2 similarly shows that patients tended to become free of symptoms earlier in the trial if they had received carbenoxolone than if they had received placebo, and the difference between the groups is again statistically significant by four to six weeks and by six weeks (by two weeks: $\chi^{2}=$ $0.38 \mathrm{NS}$; by two to four weeks: $\chi^{2}=6.28, \mathrm{P}<0.025$; by two to six weeks: $\chi^{2}=9 \cdot 76, \mathrm{P}<0.005 ; \mathrm{n}=1$ ).

Episodes of pain each day also tended to be less severe and less frequent in those receiving the active remedy and the Figure compares the average number of attacks per day in those receiving carbenoxolone and those receiving placebo.

Side-effects of undue weight gain, raised blood pressure, or hypokalaemia were noted in 15 patients receiving the active treatment $(28 \%)$ and in three of the controls $(6 \cdot 12 \%)$. Five of those receiving carbenoxolone capsules gained $4 \mathrm{~kg}$ or more in weight and oedema was detectable in three of these. Systolic or diastolic blood pressure rose by $20 \mathrm{mmHg}$ or more in 11 patients and serum potassium concentrations fell by $0.5 \mathrm{mMol} / 1$ or more in eight patients. In the control patients blood pressure rose unduly in one, and serum potassium levels fell in two other patients. No other consistent changes were noted either on clinical examination of the patients or in the laboratory analyses. None of the side-effects noted was severe enough to warrant discontinuation of the treatment, and accessory diuretic treatment or potassium supplementation were required only occasionally.

\section{Discussion}

The results obtained in this trial clearly show that treatment with carbenoxolone sodium capsules will accelerate the healing of duodenal ulceration, and that this healing is paralleled by the remission of symptoms. These findings agree with those obtained by others who obtained evidence of symptomatic benefit (Craig et al., 1967) or endoscopic improvement (Archambault et al., 1975), and similar though statistically insignificant trends towards improvement were noted by others in terms of earlier endoscopic improvement (Brown et al., 1972) or radiological improvement (Montgomery et al., 1968). Our results show more convincing evidence of benefit to those receiving carbenoxolone capsules than has usually been obtained in the past, and this reflects the large number of patients who were studied as well as the reliance which we placed upon endoscopic criteria for assessment. Attempts have been made in

Table 1 Endoscopic assessment

\begin{tabular}{|c|c|c|c|c|c|}
\hline \multirow[t]{2}{*}{ Treatment capsules } & \multicolumn{5}{|l|}{ Ulcer } \\
\hline & $\begin{array}{l}\text { Completely healed } \\
\text { (grade 0) }\end{array}$ & $\begin{array}{l}\text { Almost healed } \\
\text { (grade } 1 \text { ) }\end{array}$ & $\begin{array}{l}\text { Smaller } \\
\text { (grade 2) }\end{array}$ & $\begin{array}{l}\text { No change or worse } \\
\text { (grade } 3)\end{array}$ & Total \\
\hline $\begin{array}{l}\text { Carbenoxolone } \\
\text { Placebo }\end{array}$ & $\begin{array}{r}24 \\
6\end{array}$ & $\begin{array}{l}7 \\
9\end{array}$ & $\begin{array}{l}4 \\
3\end{array}$ & $\begin{array}{r}2 \\
13\end{array}$ & $\begin{array}{l}37 \\
31\end{array}$ \\
\hline
\end{tabular}

Table 2 Symptomatic assessment

\begin{tabular}{lllllll}
\hline \multicolumn{1}{c}{ Individuals free of pain (no.) } & & & \\
Treatment & Free of pain & By 2 weeks & By 2-4 weeks & By 4-6 weeks & Unrelieved & Total \\
\hline Carbenoxolone & 3 & 14 & 33 & 38 & 5 & 46 \\
Placebo & 2 & 10 & 19 & 22 & 16 & 40 \\
\hline
\end{tabular}

*Three patients remained free of pain before and during treatment in the treated group and two in the placebo group, although they had duodenal ulcer verified by endoscopy. 
the past to demonstrate that a variety of treatments will accelerate ulcer healing at the remission of symptoms, but no convincing evidence has yet been advanced to support the use of any other agent.

Thus, anticholinergic agents have been thought by some to induce remission of ulcer symptoms or to prevent relapse (Sun, 1964; Sun and Ryan, 1970; Walan, 1970), but others have failed to show that such treatment is of any value (Trevino et al., 1967; Kaye et al., 1970; Cocking, 1972). Poor results have in the past also been reported with the use of carbenoxolone sodium capsules, but these may be attributed in part to reliance on radiological change as a measure of healing-although radiological and endoscopic findings often correlate poorly, in part to the reporting of results obtained in small groups of patients, and in part to the inevitable random scatter which will occur when multiple independent examinations of treatment value are made (Colin Jones $e t$ al., 1968; Cliff and Milton Thompson, 1970).

Salt and water retention, increase in blood pressure, and occasionally hypokalaemia are well known adverse effects of carbenoxolone treatment. Although such changes were observed in 15 out of 53 treated by carbenoxolone capsules (approximately one in four of our patients), in no case did treatment have to be stopped.

Convincing evidence that any measure affects the long-term course of gastric or duodenal ulcer has yet to be obtained. It is correspondingly uncertain whether short-term benefit associated with carbenoxolone sodium capsule treatment is likely to be maintained.

\section{References}

Archambault, A., Farley, A., Gosselin, D., and Martin, F.
(1975). Multicentre double-blind study of Duogastrone in the treatment of duodenal ulcers. In 4th Symposium on Carbenoxolone Sodium, pp. 251-255. Edited by F. AveryJones and D. V. Parke. Butterworths: London.

Brown, P., Salmon, P. R., Htut, T., and Read, A. E. (1972). A double-blind trial of carbenoxolone sodium capsules in duodenal ulcer therapy, based on endoscopic diagnosis. British Medical Journal, 3, 661-664.

Cliff, J. M., and Milton-Thompson, G. J. (1970). A doubleblind trial of carbenoxolone sodium capsules in the treatment of duodenal ulcer. Gut, 11, 167-170.

Cocking, J. B. (1972). A trial of amylopectin sulfate (SN-263) and propantheline bromide in the longterm treatment of chronic duodenal ulcer. Gastroenterology, 62, 6-10.

Colin-Jones, D. G., Lennard Jones, J. E., Howel Jones, J., Misiewicz, J. J., and Langman, M. J. S. (1968). Carbenoxolone capsules (Duogastrone) in duodenal ulcer: preliminary results of clinical and experimental studies. In Symposium on Carbenoxolone Sodium, pp. 209-216. Edited by J. M. Robson and F. M. Sullivan. Butterworths: London.

Craig, O., Hunt, T., Kimerling, J. J., and Parke, D. V. (1967). Carbenoxolone in the treatment of duodenal ulcer. Practitioner, 199, 109-111.

Kaye, M. D., Rhodes, J., Beck, P., Sweetnan, P. M., Davies, G. T., and Evans, K. T. (1970). A controlled trial of glycopyrronium and 1-hyoscyamine in the long-term treatment of duodenal ulcer. Gut, 11, 559-566.

Montgomery, R. D., Lawrence, I. H., Manton, D. J., Mendl, K., and Rowe, P. (1968). A controlled trial of carbenoxolone sodium capsules in the treatment of duodenal ulcer. Gut, 9, 704-706.

Sun, D. C. H. (1964). Long-term anticholinergic therapy for prevention of recurrences in duodenal ulcer. American Journal of Digestive Diseases, 9, 706-716.

Sun, D. C. H., and Ryan, M. L. (1970). A controlled study on the use of propantheline and amylopectin sulfate (SN-263) for recurrences in duodenal ulcer. Gastroenterology, 58, 756-761.

Trevino, H., Anderson, J., Davey, P. G., and Henley, K. S. (1967). The effect of glycopyrrolate on the course of symptomatic duodenal ulcer. American Journal of Digestive Diseases, 12, 983-987.

Walan, A. (1970). Studies in pectic ulcer disease with special reference to the effect of 1-hyoscyamine. Acta Medica Scandinavica, suppl. 516. 